\title{
LA-UR-18-22214
}

Approved for public release; distribution is unlimited.

Title: $\quad$ TA55 TRU Waste Inventory Status 030818

Author(s): $\quad$ Clemmons, James Stephen

Intended for: Distribution to NA-LA

Issued: 2018-03-15 
Disclaimer:

Los Alamos National Laboratory, an affirmative action/equal opportunity employer, is operated by the Los Alamos National Security, LLC for the National Nuclear Security Administration of the U.S. Department of Energy under contract DE-AC52-06NA25396. By approving this article, the publisher recognizes that the U.S. Government retains nonexclusive, royalty-free license to publish or reproduce the published form of this contribution, or to allow others to do so, for U.S. Government purposes. Los Alamos National Laboratory requests that the publisher identify this article as work performed under the auspices of the U.S. Department of Energy. Los Alamos National Laboratory strongly supports academic freedom and a researcher's right to publish; as an institution, however, the Laboratory does not endorse the viewpoint of a publication or guarantee its technical correctness. 


\section{TA55 TRU Waste Inventory Status 030818}

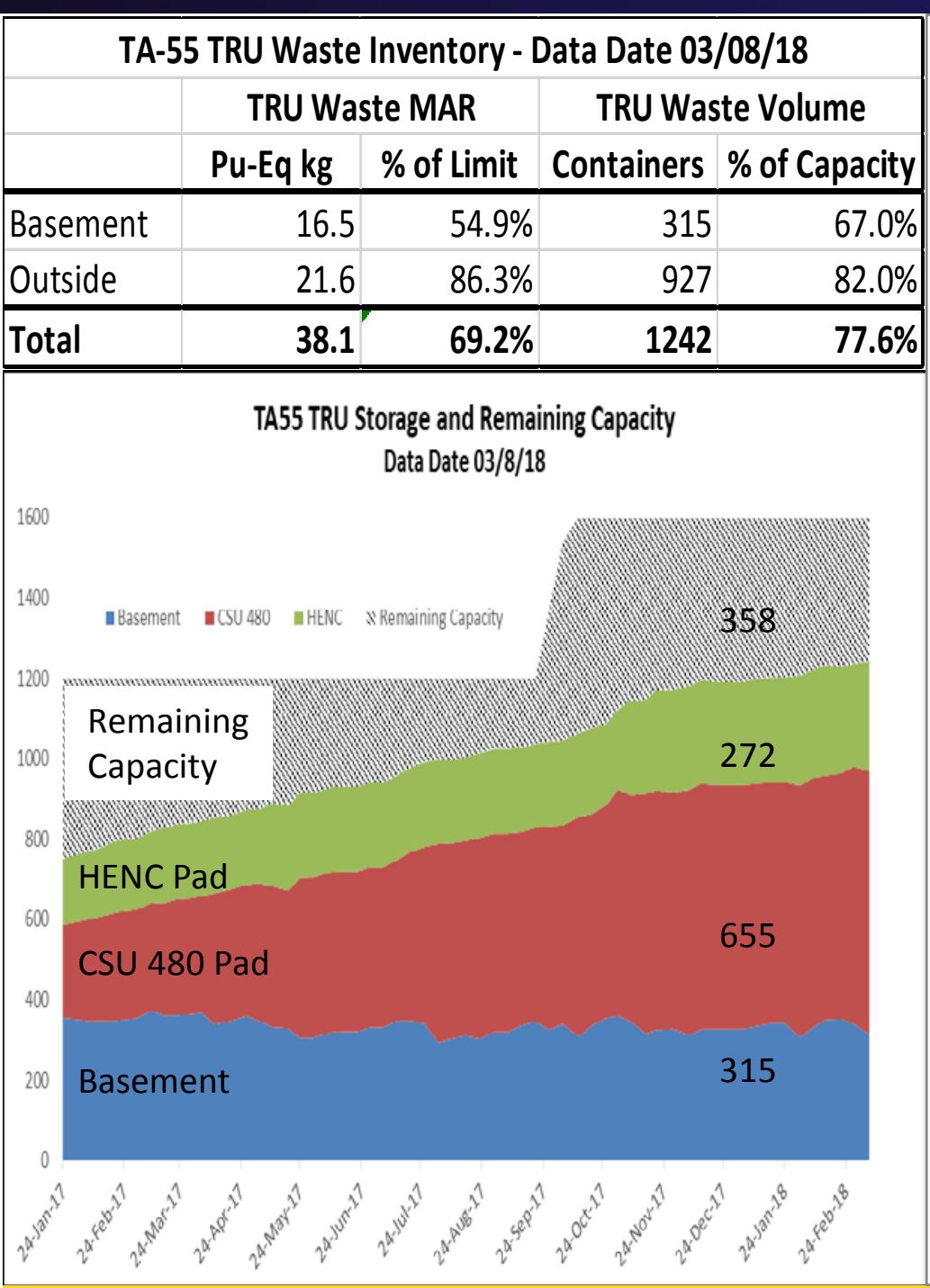

TA55 TRU Waste MAR and Storage Capacity Trend Data Date 03/8/18
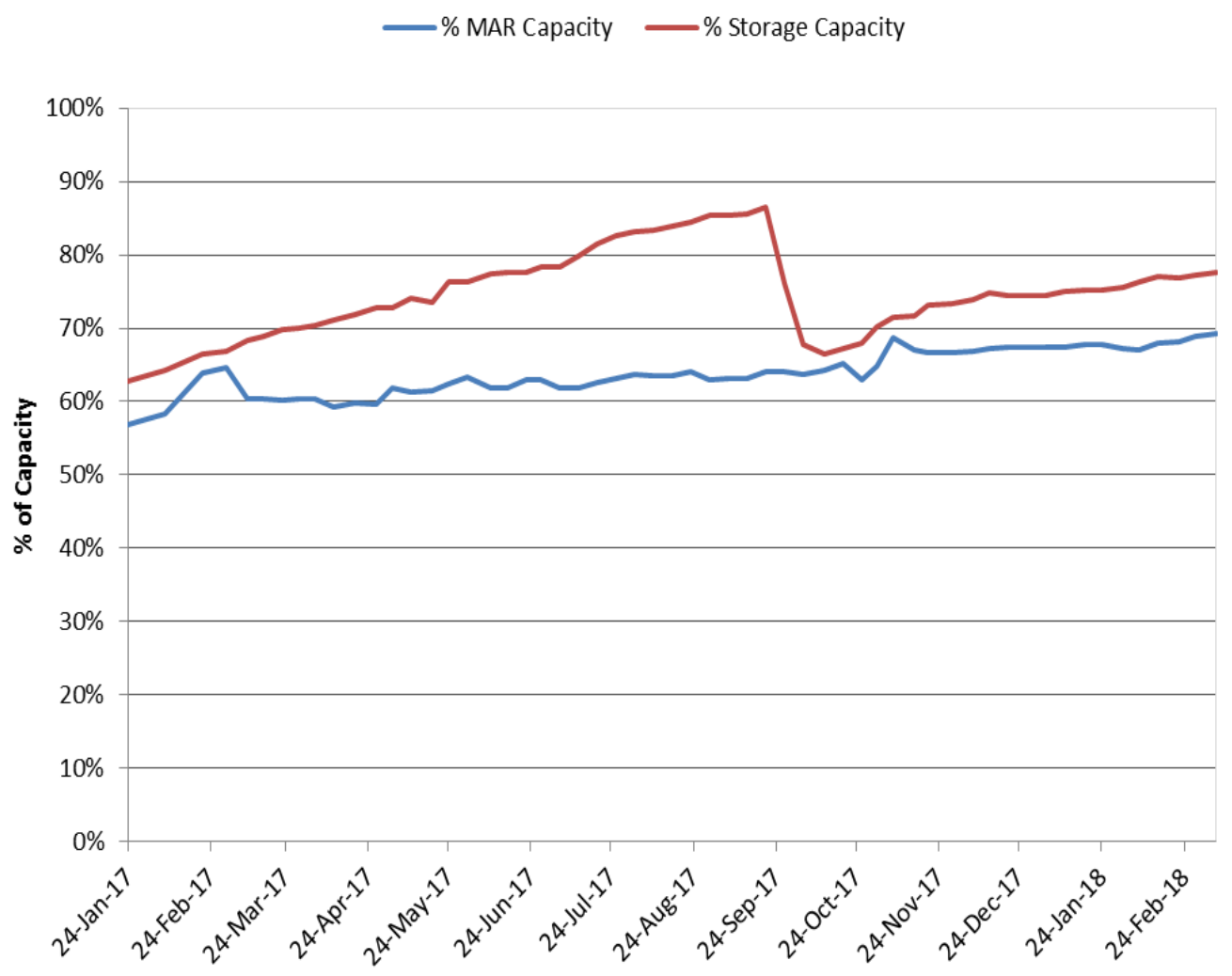

TWF inventory-28 drums, 58.7 PE-Ci.......Shipments paused due to TWF PISA 


\section{Supplemental information}

In this data set there is a correction to the $02 / 28 / 18$ container count for the HENC Pad. Nineteen containers were counted twice. The correct HENC count for $02 / 28 / 18$ is 256 vs the value of 275 that was reported. The MAR for the HENC Pad was unaffected. The overall count and remaining capacity count were adjusted accordingly.

Notes on Inventory for $03 / 08 / 18$ data date.

$\begin{array}{ll}\text { TA55 Total } & +5 \\ \text { Basement } & -25 \\ \text { CSU 480 Pad } & +14 \\ \text { HENC Pad } & +16 \\ & \\ \text { Outside MAR } & -0.66 \\ \text { Basement MAR } & +0.81\end{array}$

